\title{
ON PERTURBATION METHOD FOR THE FIRST KIND EQUATIONS: REGULARIZATION AND APPLICATION
}

\author{
I.R. Muftahov, Irkutsk State Technical University, Irkutsk, Russian Federation, \\ ildar_sm@mail.ru, \\ D.N. Sidorov, Melentiev Energy Systems Institute of Seberian Branch of Russian \\ Academy of Sciences; Irkutsk State Technical University; Irkutsk State University, \\ Irkutsk, Russian Federation, dsidorov@isem.sei.irk.ru, \\ N.A. Sidorov, Irkutsk State University, Irkutsk, Russian Federation, \\ sidorov@math.isu.runnet.ru
}

One of the most common problems of scientific applications is computation of the derivative of a function specified by possibly noisy or imprecise experimental data. Application of conventional techniques for numerically calculating derivatives will amplify the noise making the result useless. We address this typical ill-posed problem by application of perturbation method to linear first kind equations $A x=f$ with bounded operator $A$. We assume that we know the operator $\tilde{A}$ and source function $\tilde{f}$ only such as $\|\tilde{A}-A\| \leq \delta$, $\|\tilde{f}-f\|<\delta$. The regularizing equation $\tilde{A} x+B(\alpha) x=\tilde{f}$ possesses the unique solution. Here $\alpha \in S, S$ is assumed to be an open space in $\mathbb{R}^{n}, 0 \in \bar{S}, \alpha=\alpha(\delta)$. As result of proposed theory, we suggest a novel algorithm providing accurate results even in the presence of a large amount of noise.

Keywords: operator and integral equations of the first kind; stable differentiation; perturbation method, regularization parameter.

\section{Introduction}

Let $A$ be a bounded operator in a Banach space $X$ with range $R(A)$ in a Banach space $Y$. Consider the following linear operator equation

$$
A x=f, \quad f \in R(A) .
$$

We assume that the domain $R(A)$ can be nonclosed and Ker $A \neq\{0\}$. In many practical problems one needs to solve an approximate equation

$$
\tilde{A} x=\tilde{f}
$$

instead of exact equation. Here $\tilde{A}$ and $\tilde{f}$ are approximations of exact operator $A$ and right-hand side function $f$ is correspondingly such as

$$
\|\tilde{A}-A\| \leq \delta_{1}, \quad\|\tilde{f}-f\| \leq \delta_{2}, \quad \delta=\max \left\{\delta_{1}, \delta_{2}\right\} .
$$

The problem of solving of equation (2) is ill-posed and therefore unstable even with respect to small errors and it needs regularization in real world numerous applications. The basic results in regularization theory and methods for solving of the inverse problems have been gained in scientific schools of A.N. Tikhonov, V.I. Ivanov and M.M. Laverentiev. Nowadays, this field of contemporary mathematics promotes the developments of many interdisciplinary fields in science and technologies $[1-4,19,21,24]$. There have been 
proposed many efficient regularization methods for operator equation (1). The most efficient regularization methods are Tikhonov's method of stabilizer functional, the quasisolution method suggested by V.K. Ivanov, M.M. Laverentiev perturbation method, V.A. Morozov's discrepancy principle and other methods. Variational approaches, spectral theory, perturbation theory and functional analysis methods play the principal role in the theory . V.P. Maslov (see to [8]) has established the equivalence of existence of solution to ill-posed problem and convergence of the regularization process. There is a constant interest for regularization methods to be applied in interdisciplinary research and applications related to signal and image processing, numerical differentiation and inverse problems.

In this article we consider the regularized processes construction by introduction of the following perturbed equation

$$
A x_{\alpha}+B(\alpha) x_{\alpha}=f .
$$

In this paper we continue and upgrade the results $[2,12,18]$. It is to be noted that regularization method based on perturbed equation was first proposed by M.M. Laverentiev [4] in case of completely continuous self-adjoint and positive operator $A$ and $B(\alpha) \equiv \alpha$.

Following [17] we select the stabilizing operator (SO) $B(\alpha)$ to make solution $x_{\alpha}$ unique and provide computations stability. Let us call $\alpha \in S \subset \mathbb{R}^{n}$ as vector parameter of regularization. Here $S$ is an open set, with zero belonging to the boundary of this set (briefly, S-sectoral neighborhood of zero in $\mathbb{R}^{n}$ ), $\lim _{S \ni \alpha \rightarrow 0} B(\alpha)=0$. Parameter $\alpha$ we adjust to the data error level $\delta$. Similar approach was suggested in the monographs $[12,17]$, but in this article the regularization parameter $\alpha$ can be a vector. Previously only the simple case has been considered with $B(\alpha)=B_{0}+\alpha B_{1}, \alpha \in \mathbb{R}^{+}$. Such SO has been employed in the development and justification of iterative methods for Fredholm points $\lambda_{0}$, zeros and the elements of the generalized Jordan sets of operator functions [6,11] calculation, for the construction of approximate methods in the theory of branching of solutions of nonlinear operator equations with parameters [13,15-17], for construction of solutions of differential-operator equations with irreversible operator coefficient in the main part [17]. In present article we propose the novel theory for operator systems regularization.

The paper is organized as follows. In Sec. 1 we obtained the sufficient conditions when perturbed equation (4) enables a regularization process. In Sec. 2 we suggested the choice of SO $B(\alpha)$. An important role is played by a classic Banach - Steinhaus theorem. In Sec. 3 we consider the application of regularizing equation of the form (4) in the problem of stable differentiation.

\section{The Fundamental Theorem of Regularization by the Perturbation Method}

Apart from equations (1), (2), (4) introduce the equations

$$
\begin{aligned}
& (A x+B(\alpha)) x=\tilde{f}, \\
& (\tilde{A} x+B(\alpha)) x=\tilde{f} .
\end{aligned}
$$

Errors of operator $B(\alpha)$ can be always included into operator $\tilde{A}$. Equation (6) is call a regularized equation (RE) for problem (2). The following estimates are assumed to be 
fulfilled below

$$
\begin{gathered}
\left\|(A+B(\alpha))^{-1}\right\| \leq c(|\alpha|), \\
\|B(\alpha)\| \leq d(|\alpha|),
\end{gathered}
$$

where $c(|\alpha|)$ is a continuous function, $\alpha \in S \subset \mathbb{R}^{n}, 0 \in \bar{S}, \lim _{|\alpha| \rightarrow 0} c(|\alpha|)=\infty, \lim _{|\alpha| \rightarrow 0} d(|\alpha|)=$ 0 . If $x^{*}$ is a solution to equation (1), then $(A+B(\alpha))^{-1} f-x^{*}=(A+B(\alpha))^{-1} B(\alpha) x^{*}$. Therefore, we have

Lemma 1. Let $x^{*}$ be some solution to equation (1), $x(\alpha)$ satisfy equation (4). Then, in order to $x_{\alpha} \rightarrow x^{*}$ for $S \ni \alpha \rightarrow 0$ it is necessary and sufficient to have the following equality fulfilled

$$
S\left(\alpha, x^{*}\right)=\left\|(A+B(\alpha))^{-1} B(\alpha) x^{*}\right\| \rightarrow 0 \text { for } S \ni \alpha \rightarrow 0 .
$$

In [5] there are sufficient conditions for ensuring estimates (7) - (8), and examples addressing case of vector parameter. Application of such estimates for solving nonlinear equations are also considered. Let us follow [12] and introduce the following definition.

Definition 1. Condition (9) is called a stabilization condition. Operator $B(\alpha)$, is called a stabilization operator if it satisfies the condition (9). Solution $x^{*}$ is called a B-normal solution of equation (1).

Remark 1. Obviously the limit of the sequence $\left\{x_{\alpha}\right\}$ is unique in a normed space and therefore equation (1) can have only one $B$-normal solution.

From estimates $(7)-(8)$ it follows

Lemma 2. Let $x_{\alpha}$ and $\hat{x}_{\alpha}$ be solutions of equations (4) and (5) correspondingly. If parameter $\alpha=\alpha(\delta) \in S$ is selected such as $\delta \rightarrow 0$

$$
|\alpha(\delta)| \rightarrow 0 \text { and } \delta c(|\alpha(\delta)|) \rightarrow 0
$$

then $\lim _{\delta \rightarrow 0}\left\|x_{\alpha}-\hat{x}_{\alpha}\right\|=0$.

Definition 2. Condition (10) is called a coordination condition of vector parameter $\alpha$ with error level $\delta$.

The coordination conditions play a principal role in all regularization methods for illposed problems (see, e.g. $[2,4,7,10,12,17,19,23]$ ). The coordination condition is assumed to be fulfilled. Below we also assume that $\alpha$ depends on $\delta$ but for the sake of brevity we omit this fact.

Lemma 3. Let estimates (7) - (8) be satisfied as well as coordination condition for the regularization parameter (10). Next, we select $q \in(0,1)$ and find $\delta>0$ such as for $\delta \leq \delta_{0}$ the following inequality

$$
\delta c(|\alpha|)) \leq q
$$

holds. Then $\tilde{A}+B(\alpha)$ is a continuously invertible operator and the following estimates are fuilfilled

$$
\left\|(\tilde{A}+B(\alpha))^{-1}\right\| \leq \frac{\left\|(A+B(\alpha))^{-1}\right\|}{1-q}
$$




$$
\left\|(\tilde{A}+B(\alpha))^{-1} f\right\| \leq\left\|(A+B(\alpha))^{-1} f\right\|+\delta \frac{c(|\alpha|)}{1-q}\left\|(A+B(\alpha))^{-1} f\right\| .
$$

Proof. Based on estimate (3) for arbitrary $f$ we have

$$
\left\|(\tilde{A}-A)(A+B(\alpha))^{-1} f\right\| \leq \delta\left\|(A+B(\alpha))^{-1} f\right\| .
$$

Hence taking into account estimates (7), (8), (11), we have the following inequality

$$
\left\|(\tilde{A}-A)(A+B(\alpha))^{-1} f\right\| \leq \delta c(|\alpha|) \leq q\|f\| .
$$

Now, since $q \leq 1$ we have $\tilde{A}+B(\alpha)=\left(I+(\tilde{A}-A)(A+B(\alpha))^{-1}\right)(A+B(\alpha))$. Then existence of inverse operator $(\tilde{A}+B(\alpha))^{-1}$, as well as estimate (12) follows from known inverse operator Theorem. Next, we employ the following operator identity $C^{-1}=D^{-1}-$ $D^{-1}\left(I+(C-D) D^{-1}\right)^{-1}(C-D) D^{-1}$ where $C=(\tilde{A}+B(\alpha)), D=A+B(\alpha)$ and, using on inequalities (14), (15) we get estimate (13).

Theorem 1. [Main Theorem] Let conditions of Lemma 3 be fulfilled, i.e parameter $\alpha$ is coordinated with noise level $\delta$. Then $R E(6)$ has a unique solution $\tilde{x}_{\alpha}$. Moreover if in addition $x^{*}$ is a solution of exact equation (1), then the following estimate is fulfilled

$$
\left\|\tilde{x}_{\alpha}-x^{*}\right\| \leq S\left(\alpha, x^{*}\right)+\frac{\delta c(|\alpha|)}{1-q}\left(1+\left\|x^{*}\right\|+S\left(\alpha, x^{*}\right)\right) .
$$

If also $x^{*}$ is a B-normal solution of equation (1) then $\left\{\tilde{x}_{\alpha}\right\}$ converges to $x^{*}$ at a rate determined by (16) as $\delta \rightarrow 0$.

Proof. Existence and uniqueness of the sequence $\left\{\tilde{x}_{\alpha}\right\}$ as a solution of RE (6) for $\alpha \in S$ was proved in Lemma 3. Since $(\tilde{A}+B(\alpha))\left(\tilde{x}_{\alpha}-x^{*}\right)=\tilde{f}-f-(\tilde{A}-A) x^{*}-B(\alpha) x^{*}$, then we get the desired estimate (16) $\left\|\tilde{x}_{\alpha}-x^{*}\right\| \leq\left\|(\tilde{A}+B(\alpha))^{-1}\right\|\left(\|\tilde{f}-f\|+\left\|(\tilde{A}-A) x^{*}\right\|+\right.$ $\left.\left\|(\tilde{A}+B(\alpha))^{-1} B(\alpha) x^{*}\right\|\right) \leq S\left(\alpha, x^{*}\right)+\frac{\delta c(|\alpha|)}{1-q}\left(1+\left\|x^{*}\right\|+S\left(\alpha, x^{*}\right)\right)$ based on estimates (12), (13) and (8). Since $x^{*}$ is a $B$-normal solution then $\lim _{\alpha \rightarrow 0} S\left(\alpha, x^{*}\right)=0$. And thanks to parameter $\alpha$ coordinated with noise level $\delta$ we have $\lim _{\delta \rightarrow 0} \delta c(|\alpha|)=0$. Hence, due to (16) $\lim _{\delta \rightarrow 0}\left\|\tilde{x}_{\alpha}-x^{*}\right\|=0$ which completes the proof.

As footnote of the section it's to be mentioned that for practical applications of this theorem one needs recommendations on the choice of $\mathrm{SO} B(\alpha)$ and a $B$ normal solution existence conditions. It's also useful to know the necessary and sufficient conditions of existence of a $B$-normal solution $x^{*}$ to the exact equation (1). These issues we discuss below.

\section{Stabilizing Operator $B(\alpha)$ Selection, $B$-Normal Solutions Existence and Correctness Class of Problem (1)}

If $A$ is a Fredholm operator, $\left\{\phi_{i}\right\}_{1}^{n}$ is a basis in $\mathcal{N}(A),\left\{\psi_{i}\right\}_{1}^{n}$ is a basis in $\mathcal{N}^{*}(A)$, then (see Sec. 22 in [22]) one may assume $B(\alpha) \equiv \sum_{i=1}^{n}\left\langle\cdot, \gamma_{i}\right\rangle z_{i}$, where $\left\{\gamma_{i}\right\},\left\{z_{i}\right\}$ are selected such as 
$\operatorname{det}\left[\left\langle\phi_{i}, \gamma_{k}\right\rangle\right]_{i, k=1}^{n} \neq 0,\left\langle z_{i}, \psi_{i}\right\rangle=\left\{\begin{array}{ll}1 & \text { if } i=k \\ 0 & \text { if } i \neq k\end{array}\right.$ herewith the equation

$$
A x=f-\sum_{i=1}^{n}\left\langle f, \psi_{i}\right\rangle z_{i}
$$

is resolvable for arbitrary source function $f$. Let us now recall $\tilde{f}$, which is a $\delta$-approximation of $f$. Then perturbed equation $A x+\sum_{i=1}^{n}\left\langle x, \gamma_{i}\right\rangle z_{i}=\tilde{f}-\sum_{i=1}^{n}\left\langle\tilde{f}, \psi_{i}\right\rangle z_{i}$ has a unique solution $\tilde{x}$ such as $\left\|\tilde{x}-x^{*}\right\| \rightarrow 0$ for $\delta \rightarrow 0$, where $x^{*}$ is unique solution of exact equation (17) for which $\left\langle x^{*}, \gamma_{i}\right\rangle=0, i=\overline{1, n}$. Thus, in the case of a Fredholm operator $A$ as a stabilizing operator one can take a finite-dimensional operator $B=\sum_{1}^{n}\left\langle\cdot, \gamma_{i}\right\rangle z_{i}$ which does not depend on parameter $\alpha$. That is the regularization of iterative methods we employed in our papers $[9,15-17]$ for the study of the second order nonlinear equations with parameters. Of course, with this choice of SO $B$ it is required to have information about the kernel of operator $A$ and its defect subspace. Therefore, it is of interest to give recommendations on the choice of SO $B(\alpha)$ without the use of such information. In solving more complex problem it is important to consider the first kind equations, when the range of operator $A$ is not closed. It is to be noted that in papers $[10,18]$ and in monograph $[12,17]$ we constructed the SO for the first kind equations as $B_{0}+\alpha B_{1}$ where $\alpha \in \mathbb{R}^{+}$. Below we consider the generalization of such results when $B=B(\alpha), \alpha \in S \subset \mathbb{R}^{n}$. Our previous results presented in papers $[10,12,18]$ follow from the following theorems 2 and 3 as special cases.

Theorem 2. Let $\left\|(A+B(\alpha))^{-1}\right\| \leq c(|\alpha|),\|B(\alpha)\| \leq d(|\alpha|)$ for $\alpha \in S \subset$ $\mathbb{R}^{n}, c(|\alpha|), d(|\alpha|)$ be continuous functions, $\lim _{|\alpha| \rightarrow 0} c(|\alpha|)=\infty, \lim _{|\alpha| \rightarrow 0} d(|\alpha|)=0$. Let $\lim _{|\alpha| \rightarrow 0} c(|\alpha|) d(|\alpha|)<\infty, \mathcal{N}(A)=0, \overline{R(A)}=Y$. Then the unique solution $x^{*}$ of equation (1) is a B-normal solution and operator $B(\alpha)$ is its $S O$.

Proof. First, let $B(\alpha) x^{*} \in \mathbb{R}(A)$ for $\alpha \in S$. Then there exists an element $x_{1}(\alpha)$ such as $A x_{1}(\alpha)=B(\alpha) x^{*}$. Then $(A+B(\alpha))^{-1} B(\alpha) x^{*}=(A+B(\alpha))^{-1}\left(A x_{1}(\alpha)+B(\alpha) x_{1}(\alpha)-\right.$ $\left.B(\alpha) x_{1}(\alpha)\right)=x_{1}(\alpha)-(A+B(\alpha))^{-1} B(\alpha) x_{1}(\alpha)$. Since $B(0)=0, \mathcal{N}(A)=\{0\}$ then $\lim _{S \ni \alpha \rightarrow 0} x_{1}(\alpha)=0$. It is to be noted that by condition $\left\|(A+B(\alpha))^{-1} B(\alpha)\right\| \leq c(|\alpha|) d(|\alpha|)$, where $c(|\alpha|) d(|\alpha|)$ is a continuous function such as $\lim _{|\alpha| \rightarrow 0} c(|\alpha|) d(|\alpha|)$ is finite, the $\alpha$-sequence $\left\{\left\|(A+B(\alpha))^{-1} B(\alpha) x^{*}\right\|\right\}$ is infinitesimal when $S \ni \alpha \rightarrow 0$. The sequence of operators $\left\{(A+B(\alpha))^{-1} B(\alpha)\right\}$ converges pointwise to the zero operator on the linear manifold $L_{0}=$ $\{x \mid B(\alpha) x \in R(A)\}$. Thus, we have proved that the theorem is true when $B(\alpha) x^{*} \in R(A)$. By condition $\sup _{\alpha \in S} c(|\alpha|) d(|\alpha|)<\infty$ the $\alpha$-sequence $\left\{\left\|(A+B(\alpha))^{-1} B(\alpha)\right\|\right\}$ is bounded. Therefore, the sequence of linear operators $\left\{(A+B(\alpha))^{-1} B(\alpha)\right\}$ in space $X$ converges pointwise to the zero operator on the linear manifold $L_{0}=\{x \mid B(\alpha) x \in R(A)\}$. But then, on the basis of the Banach - Steinhaus theorem we have a pointwise convergence of this operator sequence to the zero operator on the closure $\overline{L_{0}}$, i.e. when $B(\alpha) x^{*} \in \overline{R(A)}$. Since $\overline{R(A)}=Y$ and $B(\alpha) \in \mathcal{L}(X \rightarrow Y)$, then $B(\alpha) x^{*} \in Y$ and theorem 2 is proved. 
The conditions of theorem 2 can be relaxed.

Corollary 1. If $\overline{R(A)} \subset Y, \lim _{S \ni \alpha \rightarrow 0} x_{1}(\alpha)=0$ then solution $x^{*}$ of exact equation (1) is a B-normal iff $B(\alpha) x^{*} \in \overline{R(A)}$.

Remark 2. In corrolary 1 condition $\mathcal{N}(A)=\{0\}$ is not used. The set $L=\{x \mid B(\alpha) x \in$ $\overline{R(A)}\}$ in conditions of corrolary 1 defines a maximum correctness class.

It is to be noted that in theorem 2 we used the assumption on the finite limit: $\lim _{S \ni \alpha \rightarrow 0}\left\|(A+B(\alpha))^{-1}\right\|\|B(\alpha)\|$. We can also relax this limitation.

Theorem 3. Let $\left\|(A+\alpha B)^{-1}\right\| \leq c(\alpha)$, where $\alpha \in \mathbb{R}^{1}, c(\alpha):\left(0, \alpha_{0}\right] \rightarrow \mathbb{R}^{+}$is a continuous function. Suppose that there is a positive integer $n \geq 1$ such as $\lim _{\alpha \rightarrow 0} c(\alpha) \alpha^{i}=$ $\infty, i=\overline{0, n-1}, \lim _{\alpha \rightarrow 0} c(\alpha) \alpha^{n}<\infty$. Let $x_{0}$ satisfy equation (1) and in case of $n \geq 2$ there exist $x_{1}, \cdots, x_{n-1}$ which satisfy the sequence of equations $A x_{i}=B x_{i-1}, i=1, \cdots, n-1$. Then $x_{0}$ is a B-normal solution to equation (1) iff $B x_{n-1} \in \overline{R(A)}$.

Proof. Since $A x_{i}=B x_{i-1}$ we have an equality $(A+\alpha B)^{-1} \alpha B x_{0}=\alpha(A+\alpha B)^{-1}\left(A x_{1}+\right.$ $\left.\alpha B x_{1}-\alpha B x_{1}\right)=\alpha x_{1}-\alpha^{2}(A+\alpha B)^{-1} B x_{1}=\cdots=\alpha x_{1}-\alpha^{2} x_{2}+\cdots-(-1)^{n} \alpha^{n}(A+$ $\alpha B)^{-1} B x_{n-1}$, where the first $n-2$ terms located on the right hand side are infinitesimal if $\alpha \rightarrow 0$. By the Banach-Steinhaus theorem the sequence $\left\{\alpha^{n}\left\|(A+\alpha B)^{-1} B x_{n-1}\right\|\right\}$ is infinitesimal. Indeed, if $B x_{n-1} \in R(A)$, then there exists $x_{n}$ such that $A x_{n}=B x_{n-1}$. But in this case $\alpha^{n}(A+\alpha B)^{-1} B x_{n-1}=\alpha^{n}(A+\alpha B)^{-1}(A+\alpha B-\alpha B) x_{n}=\alpha^{n} x_{n}-$ $\alpha^{n+1}(A+\alpha B)^{1} B x_{n}$, where $\alpha^{n+1}\left\|(A+\alpha B)^{1} B x_{n}\right\| \leq \alpha^{n+1} c(\alpha)\left\|B x_{n}\right\|, \lim _{\alpha \rightarrow 0} \alpha^{n+1} c(\alpha)=0$. Consequently, $\left\{\left\|\alpha^{n}(A+\alpha B)^{1} B x_{n-1}\right\|\right\}$ is infinitesimal, and the sequence of linear operators $\left\{\alpha^{n}(A+\alpha B)^{1} B\right\}$ pointwise converges to zero operator on the linear manifold $L=\{x \mid B x \in$ $R(A)\}$ and the sequence $\left\{\left\|\alpha^{n}(A+\alpha B)^{1} B\right\|\right\}$ is bounded. Since $I=\{x \mid B x \in \overline{R(A)}\}$ we complete the proof by the reference to the Banach-Steinhaus theorem.

We apply theorem 2 for construction of the stable differentiation algorithm below.

\section{On Differentiation Regularization}

Let $y: I \subset \mathbb{R} \rightarrow \mathbb{R}$ be continuous and differentiable function on the interval $I$, and let its derivative $y^{\prime}(t)$ be continuous on the interval $(a, b) \subset I$. Then $y(t)-y(+a)-$ $y^{\prime}(+a)(t-a)=o(t-a)$ when $t \rightarrow+a$. Let $\tilde{y}:[a, b] \rightarrow \mathbb{R}$ be a bounded function and values $c, d$ be such as $\sup _{a<t<b}|\tilde{f}(t)-f(t)|=\mathcal{O}(\delta)$, where $f(t)=y(t)-y(+a)-y^{\prime}(+a)(t-a)$, $\tilde{f}=\tilde{y}(t)-c-d(t-a)$. In applications the values $\tilde{y}\left(t_{i}\right)$ are usually known for $t_{i}=i h \in$ $[a, b]$ such as $\left|y\left(t_{i}\right)-\tilde{y}\left(t_{i}\right)\right|=\mathcal{O}(\delta)$. Our objective here is to find $\tilde{y}_{i}^{\prime}\left(t_{i}\right)$ with accuracy up to $\varepsilon$. Stable differentiation problem attracted many scientists including A.N. Tikhonov, V.Ya. Arsenin, V.V. Vasin, V.B. Demidovich, T.F. Dolgopolova and V.K. Ivanov. Here readers may refer to textbook [21], p. 158 and [1] for review of recent results . Introduce the following equations:

$$
\int_{a}^{t} x(s) d s=f(t)
$$




$$
\int_{a}^{t} x_{\alpha}(s) d s+\alpha x_{\alpha}(t)=\tilde{f}(t), \quad \int_{a}^{t} \tilde{x}_{\alpha}(s) d s+\alpha \tilde{x}_{\alpha}(t)=\tilde{f}(t) .
$$

Therefore here we have $A:=\int_{a}^{t}[\cdot] d s, R(A)=\left\{f(t) \in \mathcal{C}_{[a, b]}^{(1)}, f(+a)=0\right\}=: \stackrel{\circ}{\mathcal{C}}_{[a, b]}^{(1)}$, $\overline{R(A)}=\stackrel{\circ}{\mathcal{C}}_{[a, b]}, B(\alpha):=\alpha I, X=Y=\mathcal{C}_{[a, b]}$. Construct the inverse operator $(A+\alpha I)^{-1} \in$

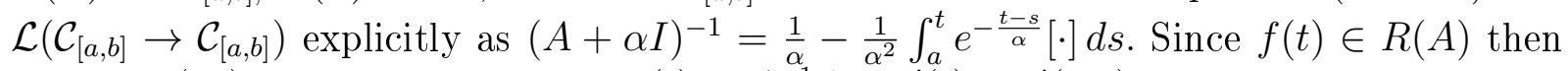
equation (18) has unique solution $x^{*}(t)=A^{-1} f \stackrel{\alpha^{2}}{=} y^{\prime}(t)-y^{\prime}(+a)$. It is to be noted that

$$
\left\|(A+\alpha I)^{-1}\right\|_{\mathcal{L}\left(\mathcal{C}_{[a, b]} \rightarrow \mathcal{C}_{[a, b]}\right)} \leq \frac{1}{\alpha}\left(1+\frac{1}{\alpha} \max _{a \leq t \leq b} \int_{a}^{t} e^{-\frac{t-s}{\alpha}} d s\right)=\frac{1}{\alpha}\left(2-e^{-\frac{a-b}{\alpha}}\right)<\frac{2}{\alpha} .
$$

Parameter $\alpha$ should be coordinated with $\delta$, e.g. $\alpha=\sqrt{\delta}$. Since $\|B(\alpha)\|=\alpha, c(\alpha)=\frac{2}{\alpha}$, $\mathcal{N}(A)=\{0\}$ then based on theorem 2 a continuous function $x^{*}(t)=y^{\prime}(t)-y^{\prime}(+a)$ is a $B$-normal solution iff $x^{*}(t) \in \overline{R(A)}$. In our case $R(A)=\stackrel{\circ}{\mathcal{C}}_{[a, b]}^{(1)}$. Taking into account that linear functions space $\stackrel{\circ}{\mathcal{C}}_{[a, b]}^{(1)}$, is dense in $L_{1}=\left\{f(t) \in \mathcal{C}_{[a, b]}, f(+a)=0\right\}, x^{*}(+a)=0$, then $x^{*}(t) \in \overline{R(A)}$. Therefore based on the Main theorem and theorem 2, the formula

$$
\tilde{x}_{\alpha}(t)=\frac{\tilde{y}(t)-c-d(t-a)}{\alpha}-\frac{1}{\alpha^{2}} \int_{a}^{t} e^{-\frac{t-s}{\alpha}}(\tilde{y}(s)-c-d(s-a)) d s
$$

defines algorithm of stable differentiation $\tilde{y}^{\prime}(t)$. Or, more precisely $\forall \varepsilon>0 \exists \delta_{0}=\delta_{0}(\varepsilon)>0$ such as, if $\sup _{a<t<b}|\tilde{f}(t)-f(t)| \leq \delta, \delta \leq \delta_{0}(\varepsilon)$ then $\max _{a \leq t \leq b}\left|\tilde{x}_{\alpha}(t)-f^{\prime}(t)\right| \leq \varepsilon$. If we select $\alpha=\sqrt{\delta}$, then $\lim _{\delta \rightarrow 0} \max _{a \leq t \leq b}\left|\tilde{x}_{\alpha}(t)-\left(y^{\prime}(t)-y^{\prime}(+a)\right)\right|=0$. Therefore, $\left\{\tilde{x}_{\alpha}\right\}$ converges uniformly to $y^{\prime}(t)-y^{\prime}(+a)$ as $\delta \rightarrow 0$. Based on (19) we constructed a regularized differentiation algorithm, which is uniform w.r.t. $t \in[a, b]$. Let us demonstrate its efficiency below.

\section{Numeric Examples}

In this section two examples are included to demonstrate the efficiency of our approach. We add noise to exact data as $\tilde{y}(t)=y(t)+\delta R(t)$ with the noise levels $\delta=0,1, \delta=0,01$ and $\delta=0,001$, where $R(t)$ is a random function with zero mean value and standard deviation $\sigma=1$. The number of used grid points is 512. Trapezoidal quadrature rule is used.

Example 1. For the first example we use the function $y(t)=\frac{1}{t^{3}+1} \sin \left(\frac{\pi t}{4}\right), t \in[0,3]$, with its derivative $y^{\prime}(t)=\frac{-3 t^{2}}{\left(t^{3}+1\right)^{2}} \sin \left(\frac{\pi t}{4}\right)+\frac{\pi}{4\left(t^{3}+1\right)} \cos \left(\frac{\pi t}{4}\right)$. Fig. 1 demonstrates precise and computed derivatives and the errors for noise level $\delta=0,001$. The maximum errors are given in Tab. 1.

\section{Table 1}

\begin{tabular}{|c|c|c|c|}
\hline$\delta$ & 0,1 & 0,01 & 0,001 \\
\hline max error & 0,172977091 & 0,284849645 & 0,70584444 \\
\hline
\end{tabular}

Example 2. Here we used the exact function $y(t)=\cos \left(\frac{\pi t}{8}\right) e^{-t^{2}}, t \in[0,5]$, with its exact derivative $y^{\prime}(t)=-e^{-t^{2}}\left(\frac{\pi}{8} \sin \left(\frac{\pi t}{8}\right)+2 t \cos \left(\frac{\pi t}{8}\right)\right)$. In Fig. 2 we compare precise and computed 


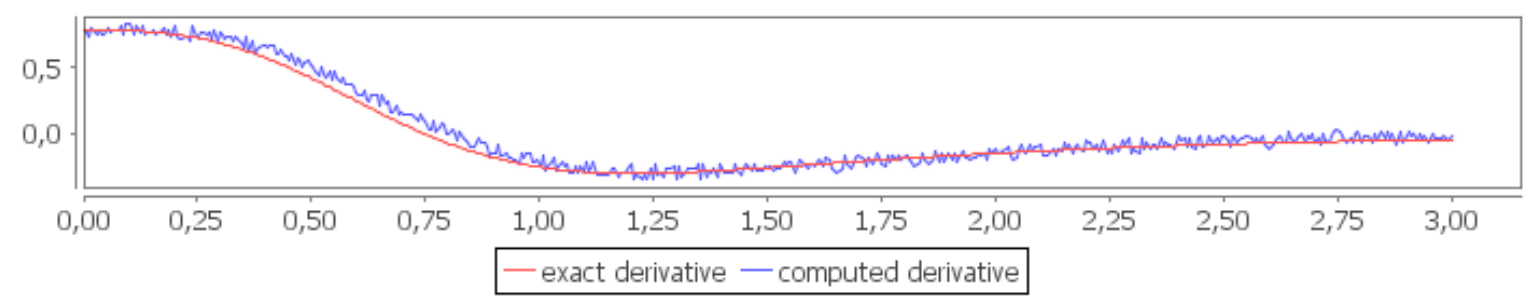

(a)

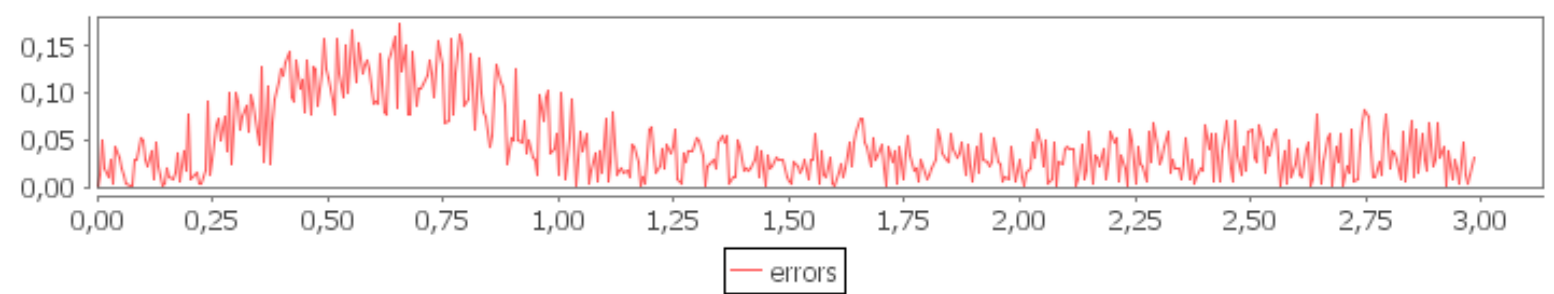

(b)

Fig. 1. Example 1: (a) the precise and the computed derivatives $\tilde{y}^{\prime}(t)$, (b) the errors. The noise level $\delta=0,001$ is used to generate $\tilde{y}(t)$

derivatives and analyse the errors with the noise level $\delta=0,001$. The maximum errors for this example are shown in Tab. 2.

Table 2

\begin{tabular}{|c|c|c|c|}
\hline$\delta$ & 0.1 & 0.01 & 0.001 \\
\hline max error & 0,169489112 & 0,277548421 & 0,637657088 \\
\hline
\end{tabular}

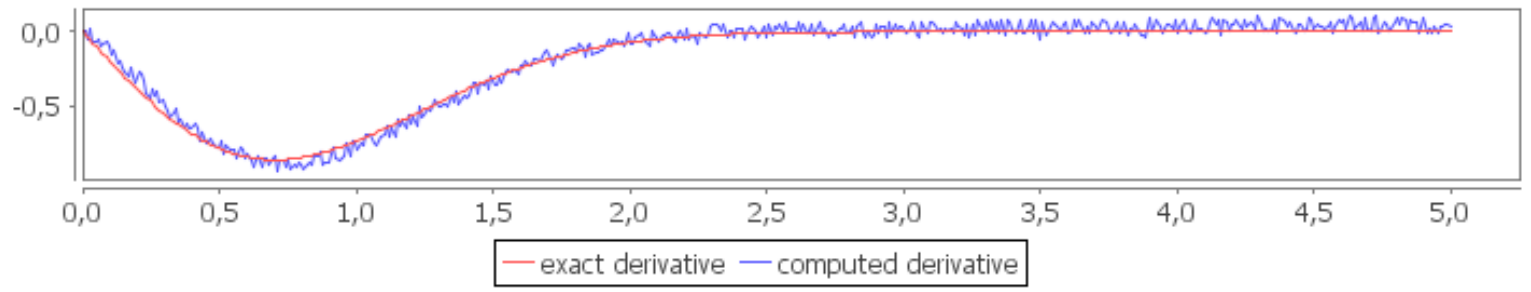

(a)

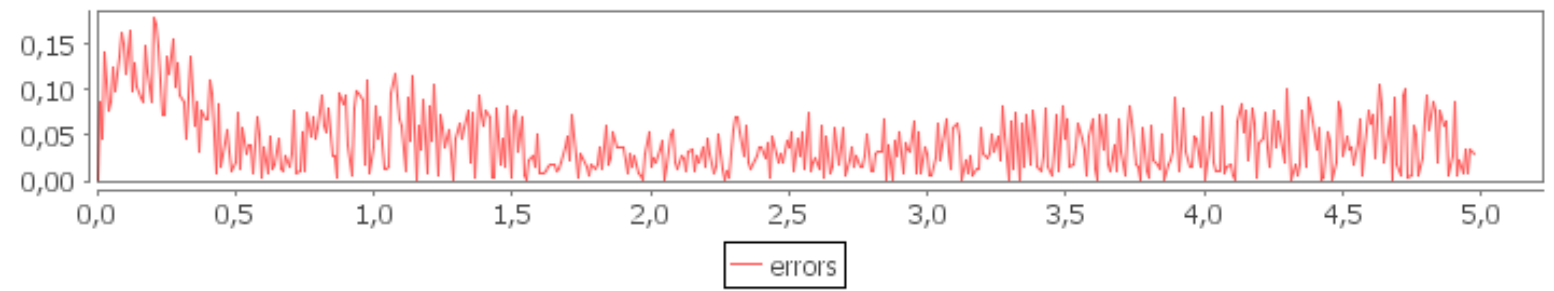

(b)

Fig. 2. Example 2: (a) the precise and the computed derivatives $\tilde{y}^{\prime}(t)$, (b) the errors. The noise level $\delta=0,001$ is used to generate $\tilde{y}(t)$ 


\section{References}

1. Hào N.D., Chuonga L.H., Lesnic D. Heuristic Regularization Methods for Numerical Differentiation. Computers and Mathematics with Applications, 2012, vol. 63, pp. 816-826. DOI: $10.1016 /$ j.camwa.2011.11.047

2. Ivanov V.K., Vasin V.V., Tanana V.P. The Theory of Linear Ill-posed Problems and their Applications. Moscow, Nauka, 1978. (in Russian)

3. Lattes R., Lions J.L. The Method of Quasi-Reversibility. Applications to Partial Differential Equations. American Elsevier Publishing Company, 1969.

4. Lavrentiev M.M. Some Improperly Posed Problems in Mathematical Physics. Berlin, Springer, 1967. DOI: $10.1007 / 978-3-642-88210-4$

5. Leontiev R.Yu. Nonlinear Equations in Banach Spaces with Vector Parameter in Singular Case. Irkuts State University Publ., 2013. 101 p. (in Russian)

6. Loginov B.V., Sidorov N.A. Calculation of Eigenvalues and Eigenvectors of Bounded Operators by the False-Perturbation Method. Mathematical notes of the Academy of Sciences of the USSR, 1976, vol. 19, issue 1, pp. 62-64.

7. Marchuk G.I. Perturbation Theory and the Statement of Inverse Problems. Lecture Notes in Computer Science. Vol. 4: 5th Conf. on Optimization Tech. Springer, 1973, pp. 159-166. DOI: $10.1007 / 3-540-06600-4 \_14$

8. Maslov V.P. [The Existence of a Solution of an Ill-Posed Problem is Equivalent to the Convergence of a Regularization Process]. Uspekhi Mat. Nauk, 1968, vol. 23, no. 3(141), pp. 183-184. (in Russian)

9. Sidorov D. Integral Dynamical Models: Singularities, Signals and Control. Vol. 87 of World Scientific Series on Nonlinear Science. Singapore, London, World Scientific Publ., 2014. 243 p.

10. Sidorov N.A., Trenogin V.A. Linear Equations Regularization using the Perturbation Theory. Differential Equations, 1980, vol. 16, no. 11, pp. 2038-2049.

11. Sidorov N.A. Calculation of Eigenvalues and Eigenvectors of Linear Operators by the Theory of Perturbations. (in Russian) Differential Equations, 1978, vol. 14, no 8, pp. 1522-1525.

12. Sidorov N.A. General Issues of Regularisation in the Problems of the Theory of Branching. Irkutsk State University Publ., Irkutsk, 1982. 312 p. (in Russian)

13. Sidorov N.A. Explicit and Implicit Parametrisation of the Construction of Branching Solutions by Iterative Methods. Sbornik: Mathematics, 1995, vol. 186, no. 2, pp. 297-310. DOI: 10.1070/SM1995v186n02ABEH000017

14. Sidorov N.A., Leont'ev R.Yu., Dreglya A.I. On Small Solutions of Nonlinear Equations with Vector Parameter in Sectoral Neighborhood. Mathematical Notes, 2012, vol. 91, no. 1-2, pp. 90-104. DOI: 10.1134/S0001434612010105

15. Sidorov N.A., Sidorov D.N. Solving the Hammerstein Integral Equation in Irregular Case by Successive Approximations. Siberian Mathematical Journal, March 2010, vol. 51, no. 2, pp. 325-329. DOI: $10.1007 /$ s11202-010-0033-4

16. Sidorov N.A., Sidorov D.N., Krasnik A.V. On Solution of the Volterra Operator-Integral Equations in Irregular Case using Successive Approximations. Differential Equations, 2010, vol. 46, no. 6, pp. 874-882. DOI: 10.1134/S001226611006011X

17. Sidorov N., Loginov B., Sinitsyn A., Falaleev M. Lyapunov - Schmidt Methods in Nonlinear Analysis and Applications. Dortrecht, Kluwer Academic Publ., 2002. 548 p. DOI: $10.1007 / 978-94-017-2122-6$

18. Sidorov N.A., Trenogin V.A. A Certain Approach the Problem of Regularization of the Basis of the Perturbation of Linear Operators. Mathematical Notes of the Academy of Sciences of the USSR, 1976, vol. 20, no. 5, pp. 976-979. 
19. Sizikov V. S. Further Development of the New Version of a Posteriori Choosing Regularization Parameter in Ill-Posed Problems. International Journal of Artificial Intelligence, 2015, vol. 13, no. 1 , pp. 184-199.

20. Stechkin S.B. The Best Approximation of Linear Operators. Mathematical Notes, 1967, vol. 1, no. 2 , pp. $137-148$. DOI: $10.1007 /$ BF 01268056

21. Tikhonov A.N., Arsenin V.Ya. Solutions of Ill-Posed Problems. N.Y., Wiley, 1977.

22. Trenogin V.A. Functional Analysis. Moscow, Nauka, 1980. 496 p. (in Russian)

23. Trenogin V.A., Sidorov D.N. Regularization of Computation of Branching Solution of Nonlinear Equations. Lecture Notes in Mathematics. 1977, vol. 594, pp. 491-506.

24. Yagola A.G. Inverse Problems and Methods of Their Solution. Applications to Geophysics. Moscow, Binom, 2014. 216 p. (in Russian)

This work was partly supported by RFBR, project №15-58-10063.

Received March 11, 2015

УДК 517.983

DOI: $10.14529 / \mathrm{mmp} 150206$

\title{
МЕТОД ВОЗМУЩЕНИЙ В РЕГУЛЯРИЗАЦИИ УРАВНЕНИЙ ПЕРВОГО РОДА И ПРИЛОЖЕНИЯ
}

\author{
И.Р. Муфтахов, Д.Н. Сидоров, Н.А. Сидоров
}

\begin{abstract}
Одной из распространенных задач, возникающих в различных приложениях, является задача вычисления производной функции, заданной в виде зашумленных или неточно заданньх экспериментальных данных. Использование стандарных методов в таких случаях усиливает исходный шум, делая результаты дифференцирования бесполезными для практических приложений. В данной работе эта типичная некорректная задача рассмотрена с точки зрения теории линейных операторных уравнений первого рода. Метод возмущений применяется к линейным уравнениям первого рода $A x=f$. Предполагается, что оператор $\tilde{A}$ и функция $\tilde{f}$ заданы приближенно. Построено регуляризирующее уравнение $\tilde{A} x+B(\alpha) x=\tilde{f}$, которое имеет единственное решение. Здесь $\alpha \in S$, где $S$ предполагается открытым множеством в $\mathbb{R}^{n}, 0 \in \bar{S}, \alpha=\alpha(\delta)$. Строится алгоритм устойчивого численного дифференцирования, позволяющий получать устойчивые результаты в случае сильно зашумленных исходных данных.
\end{abstract}

Ключевые слова: операторное уравнение первого рода; численное дифферениирование; метод возмущений; параметр регуляризачии.

\section{Литература}

1. Hào, N.D. Heuristic Regularization Methods for Numerical Differentiation / N.D. Hào, L.H. Chuonga, D. Lesnic // Computers and Mathematics with Applications. - 2012. - V. 63. P. $816-826$.

2. Иванов, В.К. Теория линейных некорректных задач и ее приложения / В.К. Иванов, В.В. Васин, В.П. Танана. - М.: Наука, 1978.

3. Латтес, Р. Метод квазиобращения и его приложения / Р. Латтес, Ж.Д. Лионс. - М.: Мир, 1970.

4. Лаврентьев, М.М. О некоторых некорректных задачах математической физики М.М. Лаврентьев. - Новосибирск: Наука, 1962. - 125 с. 
5. Леонтьев, Р.Ю. Нелинейные уравнения в банаховых пространствах с векторным параметром в нерегулярном случае / Р.Ю. Леонтьев. - Иркутск: Изд-во ИГУ, 2013. - 101 с.

6. Логинов, Б.В. Вычисление собственных чисел и векторов ограниченных операторов методом ложных возмущений / Б.В. Логинов, Н.А. Сидоров // Математические заметки. 1976. - Т. 19, № 1. - C. 105-108.

7. Marchuk, G.I. Perturbation Theory and the Statement of Inverse Problems / G.I. Marchuk // Lecture Notes in Computer Science. Vol. 4: 5th Conf. on Optimization Tech. - 1973. P. $159-166$.

8. Маслов, В.П. Существование решения некорректной задачи эквивалентно сходимости регуляризованного процесса / В.П. Маслов // Успехи математических наук. - 1968. Т. 141, вып. 23 (3). - C. 183-184.

9. Sidorov, D. Integral Dynamical Integral Dynamical Models: Singularities, Signals and Control / D. Sidorov. - Singapor; London: World Scientific Publ., 2014. - V. 87 of World Scientific Series on Nonlinear Science, Series A. - 243 p.

10. Сидоров, Н.А. Регуляризация линейных уравнений на основе теории возмущений Н.А. Сидоров, В.А. Треногин // Дифференциальные уравнения. - 1980. - Т. 16, № 11.C. 2038-2049.

11. Сидоров, Н.А. Вычисление собственных чисел и векторов линейных операторов на основе теории возмущений / Н.А. Сидоров // Дифференциальные уравнения. - 1978. T. 14, № 8. - C. 1522-1525.

12. Сидоров, Н.А. Общие вопросы регуляризации в задачах теории ветвления / Н.А. Сидоров. - Иркутск: Изд-во ИГУ, 1982. - 312 с.

13. Сидоров, Н.А. Явная и неявная параметризация при построении разветвляющихся решений итерационными методами / Н.А. Сидоров / / Математический сборник. - 1995. Т. 186, № 6 . - С. 129-144.

14. Сидоров, Н.А. О малых решениях нелинейных уравнений с векторным параметром в секториальных окрестностях / Н.А. Сидоров, Р.Ю. Леонтьев, А.И. Дрегля // Математические заметки. - 2012. - Т. 91, вып. 1. - С. 120-135.

15. Сидоров, Н.А. О решении интегрального уравнения Гаммерштейна в нерегулярном случае методом последовательных приближений / Н.А. Сидоров, Д.Н. Сидоров // Сибирский математический журнал. - 2010. - Т. 51, № 2. - С. 404-409.

16. Сидоров Н.А. О решении операторно-интегральных уравнений Вольтерры в нерегулярном случае методом последовательных приближений / Н.А. Сидоров, Д.Н. Сидоров, А.В. Красник // Дифференциальные уравнения. - 2010.- Т. 46, №6. - С. 874-882.

17. Sidorov N. Lyapunov - Schmidt Methods in Nonlinear Analysis and Applications / N. Sidorov, B. Loginov, A. Sinitsyn, M. Falaleev. - Dortrecht: Kluwer Academic Publ., 2002. $-548 \mathrm{p}$.

18. Сидоров, Н.А. Об одном подходе к проблеме регуляризации на основе возмущения линейных операторов / Н.А. Сидоров, В.А. Треногин // Математические заметки. 1976. - T. 40, № 5. - C. $747-752$.

19. Sizikov, V.S. Further Development of the New Version of a Posteriori Choosing Regularization Parameter in Ill-Posed Problems/ V.S. Sizikov // International Journal of Artificial Intelligence. - 2015. - V. 13, №1. - P. 184-199.

20. Стечкин, С.Б. Наилучшее приближение линейных операторов / С.Б. Стечкин // Математические заметки. - 1967. - Т. 1, № 2. - С. 137-148.

21. Тихонов, А.Н. Методы решения некорректных задач / А.Н. Тихонов, В.Я. Арсенин. М.: Наука, 1974.

22. Треногин, В.А. Функциональный анализ / В.А. Треногин. - М.: Наука, 1980. - 496 с.

Вестник ЮУрГУ. Серия «Математическое моделирование

и программирование» (Вестник ЮУрГУ ММП). 2015. Т. 8, № 2. С. 69-80 
23. Trenogin, V.A. Regularization of Computation of Branching Solution of Nonlinear Equations / V.A. Trenogin, N.A. Sidorov // Lecture Notes in Mathematics. - 1977. - V. $594 .-$ P. 491-506.

24. Ягола, А.Г. Обратные задачи и методы их решения. Приложения к геофизике / А.Г. Ягола, В. Янфей, И.Э. Степанова, В.Н. Титоркин. - М.: Бином. Сер. мат. моделирование, 2014. -216 c.

Ильдар Ринатович Муфтахов, аспирант кафедры «Вычислительная техника», Институт кибернетики им. Е.И. Попова, Иркутский государственный технический университет (г. Иркутск, Россия), ildar_sm@mail.ru.

Денис Николаевич Сидоров, кандидат физико-математических наук, старший научный сотрудник отдела «Прикладная математика», Институт систем энергетики им. Л.А. Мелентьева СО РАН, Иркутский государственный технический университет, Иркутский государственный университет, (г. Иркутск, Россия), dsidorov@isem.sei.irk.ru.

Николай Александрович Сидоров, доктор физико-математических наук, професcop, кафедра «Математический анализ и дифференциальные уравнения», Иркутский государственный университет (г. Иркутск, Россия), sidorov@math.isu.runnet.ru.

Поступила в редакцию 11 марта 2015 2. 